\title{
Two alternatively spliced GPR39 transcripts in seabream: molecular cloning, genomic organization, and regulation of gene expression by metabolic signals
}

\author{
Yong Zhang ${ }^{1, *}$, Yun Liu' ${ }^{1, *}$, Xigui Huang ${ }^{2, *}$, Xiaochun Liu' ${ }^{1, *}$, Baowei Jiao ${ }^{2}$, Zining Meng ${ }^{1}$, Pei Zhu ${ }^{1}$, \\ Shuisheng L $\mathbf{i}^{1}$, Haoran Lin ${ }^{1,3}$ and Christopher H K Cheng ${ }^{2}$ \\ ${ }^{1}$ State Key Laboratory of Biocontrol, School of Life Sciences, Institute of Aquatic Economic Animals, and the Guangdong Province Key Laboratory for Aquatic \\ Economic Animals, Sun Yat-Sen University, Guangzhou 510275, China \\ ${ }^{2}$ Department of Biochemistry, The Chinese University of Hong Kong, Shatin, N.T., Hong Kong, China \\ ${ }^{3}$ College of Ocean, Hainan University, Haikou, Hainan 570228, China \\ (Correspondence should be addressed to H Lin; Email: Isslhr@mail.sysu.edu.cn; C H K Cheng; Email: chkcheng@cuhk.edu.hk) \\ *(Y Zhang, Y Liu, X Huang and X Liu contributed equally to this work)
}

\begin{abstract}
Two GPR39 transcripts, designated as sbGPR39-1a and sbGPR 39-1b, were identified in black seabream (Acanthopagrus schlegeli). The deduced amino acid (aa) sequence of sbGPR39-1a contains 423 residues with seven putative transmembrane (TM) domains. On the other hand, sbGPR 39-1b contains 284 aa residues with only five putative TM domains. Northern blot analysis confirmed the presence of two GPR39 transcripts in the seabream intestine, stomach, and liver. Apart from seabream, the presence of two GPR39 transcripts was also found to exist in a number of teleosts (zebrafish and pufferfish) and mammals (human and mouse). Analysis of the GPR39 gene structure in different species suggests that the two GPR39 transcripts are generated by alternative splicing. When the seabream receptors were expressed in cultured HEK293 cells, $\mathrm{Zn}^{2+}$ could trigger sbGPR39-1a signaling through the serum response element
\end{abstract}

pathway, but no such functionality could be detected for the sbGPR 39-1b receptor. The two receptors were found to be differentially expressed in seabream tissues. sbGPR39-1a is predominantly expressed in the gastrointestinal tract. On the other hand, sbGPR 39-1b is widely expressed in most central and peripheral tissues except muscle and ovary. The expression of sbGPR 39-1a in the intestine and the expression of sbGPR 39-1b in the hypothalamus were decreased significantly during food deprivation in seabream. On the contrary, the expression of the $\mathrm{GH}$ secretagogue receptors (sbGHSR-1a and sbGHSR-1b) was significantly increased in the hypothalamus of the food-deprived seabream. The reciprocal regulatory patterns of expression of these two genes suggest that both of them are involved in controlling the physiological response of the organism during starvation.

Journal of Endocrinology (2008) 199, 457-470

\section{Introduction}

Subsequent to the identification of the GH secretagogue receptor (GHSR; Howard et al. 1996), other GHSR family members were discovered including GPR38 and GPR39, which belong to the class A 7 transmembrane (TM) domain G-protein-coupled receptors (GPCRs; McKee et al. 1997). GHSR was deorphanized in 1999 by the discovery of a novel gut-derived peptide ghrelin (Kojima et al. 1999). The endogenous ligand for GPR38 was also identified as a gastric peptide motilin (Feighner et al. 1999). The putative natural ligand for GPR39 was suggested to be an amidated 23-amino acid (aa) peptide designated as obestatin isolated from rat stomach (Zhang et al. 2005). However, recent studies failed to demonstrate that obestatin could bind and activate GPR39 (Lauwers et al. 2006, Chartrel et al. 2007, Gourcerol et al. 2007, Holst et al. 2007). It was suggested that the impure obestatin used in the original report might be responsible for the aberrant results (Zhang et al. 2007).

GPR39 was encoded by a single-copy gene in the human genome mapped to the chromosome location 2q21-q22 (McKee et al. 1997). Northern blot and reverse transcription PCR (RT-PCR) analyses indicated that GPR39 is predominantly expressed in the gastrointestinal tract (McKee et al. 1997, Zhang et al. 2005, Nogueiras et al. 2007, Yamamoto et al. 2007). GPR 39 is also widely expressed in the brain regions

The sequences reported in this paper have been deposited in the GenBank database at NCBI and are assigned the following accession numbers: EU076425, EU076426, EU076427, EU076428, EU076429, EU076430, EU076431, and EU076432. 
(McKee et al. 1997, Jackson et al. 2006). Interestingly, GPR39 was found to be a constitutively activated receptor acting mainly through the serum response element (SRE) pathway (Holst et al. 2004). Although the endogenous ligand for GPR39 still remains to be ascertained, $\mathrm{Zn}^{2+}$ can activate GPR39 signaling through various pathways at micromolar concentrations (Holst et al. 2004, 2007, Lauwers et al. 2006). Recently, GPR 39 knockout mice were generated. Compared with the wild-type counterpart, GPR39-deficient mice exhibit accelerated gastric emptying and reduced fastinginduced hyperphagia, suggesting a role of the receptor in gastrointestinal tract regulation (Moechars et al. 2006).

To date, the full-length cDNA sequences of GPR39 have been reported in some mammals and chicken (McKee et al. 1997, Zhang et al. 2005, Yamamoto et al. 2007). Little information is available about GPR39 in teleost fish. Thus, isolating GPR 39 from distant phylogenetic groups may help to elucidate the structural and functional evolution of GPR 39. In addition, there is little information on the presence of GPR 39 subtypes and their regulation of expression. In the present study, we have identified two GPR 39 transcripts from black seabream, namely sbGPR 39-1a and sbGPR 39-1b, derived from alternative splicing of the same gene. We have also demonstrated that this phenomenon is conserved in a variety of vertebrates from teleosts to mammals. The two seabream GPR 39 receptors were studied by transfection in cultured HEK293 cells and their expression levels investigated in different seabream tissues. GPR39 is a member of GHSR receptor family, which plays important roles in food intake and energy homeostasis (Kojima \& Kangawa 2005); thus regulation of the expression of GPR 39 and GHSR during food deprivation (FD) in seabream was also investigated.

\section{Materials and Methods}

\section{Animals}

Black seabream (Acanthopagrus schlegeli) and pufferfish (Takifugu rubripes) were obtained from the Guangdong Daya Bay Fishery Development Center (Guangdong Province, China). Zebrafish (Danio rerio) were purchased from a local fish shop. Fish were anesthetized and killed by decapitation. Tissue samples were collected immediately and snap frozen in liquid nitrogen. All the animal experiments were conducted in accordance with the guidelines and approval of the respective Animal Research and Ethics Committees at Sun Yat-Sen University and The Chinese University of Hong Kong.

\section{Molecular cloning of GPR39 cDNAs in a number of teleosts and mammals}

According to the reported mammalian GPR39 cDNA sequences and the predicted GPR39 cDNA sequences in the fish genomes, degenerate primers were designed for cloning the
GPR39 cDNA in seabream. Total RNA from seabream intestine was prepared using TRIzol reagent (Invitrogen). One microgram of total RNA was used to synthesize the firststrand cDNA following the manufacturer's instructions of the ReverTra Ace- $\alpha$ First-strand cDNA Synthesis kit (TOYOBO, Tokyo, Japan). Subsequently, a cDNA fragment of the putative seabream GPR39 (sbGPR39) was obtained.

Rapid amplifications of cDNA ends (RACE) were then performed to obtain the full-length GPR39-1a cDNA using the $5^{\prime}-$ and $3^{\prime}$-RACE amplification kits (Invitrogen). For $5^{\prime}-$ RACE, sbGPR39-1a RACE R1 and AAP were used in the first-round reaction. Then the amplified products were diluted and employed as a template for the second-round reaction using sbGPR 39-1a RACE R 2 and AUAP as primers. For 3'-RACE, sbGPR 39-1a RACE F1 and AUAP were used in the first-round reaction and sbGPR39-1a RACE F2 and AUAP were used in the second-round reaction. To confirm that the full-length cDNA sequence was correctly assembled, two gene-specific primers sbGPR 39-1a full-length $F$ and sbGPR 39-1a full-length $\mathrm{R}$ were designed to amplify the entire open reading frame (ORF) of sbGPR39-1a.

For sbGPR 39-1b, primers sbGPR39-1b RACE F1 and sbGPR 39-1b RACE F2 were used to obtain the $3^{\prime}$-end sequence. $3^{\prime}$-RACE was performed as described above using first-strand cDNA prepared from the seabream hypothalamus as the template. The full-length cDNA sequence of sbGPR39$1 \mathrm{~b}$ was eventually confirmed by PCR with a pair of genespecific primers sbGPR39-1a full-length $F$ and sbGPR 39-1b full-length R flanking the ORF of sbGPR39-1b.

Data mining was carried out for identifying the presence of the GPR 39-1b transcript by searching the genome sequence information (Ensembl Genome Browser (http://www. ensembl.org/) and NCBI database (http://www.ncbi.nlm.nih. gov/) using TBLASTN algorithm) in human (Homo sapiens: Ensembl 48, NCBI 36), mouse (Mus musculus: Ensembl 48, NCBI m37), zebrafish (D. rerio: Ensembl 48, assembly Zv7), and pufferfish (T. rubripes: Ensembl 48, FUGU 4.0). Using the deduced sbGPR 39-1a polypeptide sequence as query, putative ORFs encoding for GPR 39-1a were identified in zebrafish and pufferfish using the TBLASTN algorithm. The GPR39-1b transcripts were predicted to be encoded by the first exon of GPR 39-1a and part of the intron. To substantiate that the two GPR 39 transcripts, especially GPR 39-1b, really exist in these species, RT-PCR was performed to amplify the ORFs of the GPR39 transcripts in these species of vertebrates. Sequence information of all the primers used is listed in Table 1.

\section{Sequence and phylogenetic analyses}

Multiple alignment of aa sequences was performed using the CLUSTAL_X program. Hydrophobicity analyses were performed by the TMHMM 2.0 program (www.cbs.dtu. $\mathrm{dk} /$ services/TMHMM). Phylogenetic trees were generated using MEGA3.1 (Kumar et al. 2004). The data were resampled by 1000 bootstrap replicates to determine the confidence indices within the phylogenetic tree. 
Table 1 The primer sequences used in the present study

Sequence $\left(5^{\prime}\right.$ to $\left.3^{\prime}\right)$

Primer name

Degenerate $\mathrm{F}$

Degenerate $\mathrm{R}$

AP

AAP

AUAP

sb GPR39-1a RACE F1

sb GPR39-1a RACE F2

sb GPR39-1a RACE R1

sb GPR39-1a RACE R2

sb GPR39-1b RACE F1

sb GPR39-1b RACE F2

sb GPR39 full-length $F$

sb GPR39-1a full-length $R$

sb GPR39-1b full-length $R$

Human GPR39 full-length $F$

Human GPR39-1a full-length R

Human GPR39-1b full-length $R$

Mouse GPR39 full-length F

Mouse GPR39-1 a full-length $R$

Mouse GPR39-1b full-length $R$

Pufferfish GPR39 full-length $F$

Pufferfish GPR39-1a full-length $R$

Pufferfish GPR39-1b full-length $R$

Zebrafish GPR39 full-length $F$

Zebrafish GPR39-1a full-length $R$

Zebrafish GPR39-1b full-length $R$

Probe F

Probe R

sb GPR39-1a real-time $F$

sb GPR39-1a real-time $R$

sb GPR39-1b real-time $F$

sb GPR39-1b real-time $R$

sb GHSR-1a real-time F

sb GHSR-1a real-time R

sb GHSR-1b real-time $F$

sb GHSR-1b real-time $R$

sb GPR39-1a F

sb GPR39-1a R

sb GPR39-1b F

sb GPR39-1b R

sb-actin- $\mathrm{F}$

sb-actin-R
GGAGCTCTACAGYGCCATCTG

GTACATCACCCA GTGCTNCC

GGCCACGCGTCGACTAGTAC(oligoT 16)

GGCCACGCGTCGACTAGTAGGGGGGGGGGGG

GGCCACGCGTCGACTAGTAC CCTGCAAGA

TCTACAACTTCC

GCCCATAATCTGACGTTCTGTAC

GTAGATCTTGCAGGAAACGTTGC

ACGAGAACGGGAACCAGATGG

CCTGCAAGATCTACAACTTCC

GTTTCGCTTCAAAGCACTC

TGACTCGTGA ACTCTCTGACAG

CGCTCACCTCTGGATCTTGG

GGTTCACTTAACAGCTGGTG

GTGCTCTTTCTCATGGCTTCAC

CATTCAAACTTCATGCTCCTG

TGGGAAGCTGCTCACGTGTTG

ATGGCTTCATCCAGTGGCTC

TCATACTTCCTGCTCCTGTAA

TCAGTGAACTCCGGGTTTCAC

GAACAGAGAAGAAGACCTGAG

GACCTGAAGGATGAGACGATG

CTGTTTAGTTCACATGCAGG

ATGGACCCGCAGCAGCCGG

TCAGCTGCTTTGTTCATCAG

CTAGTGTGACCACAGGATAAG

TCGCTCACCTCTGGATCTTGG

ACGAGAACGGGAACCAGATGG

CTACATGATCGTGTTGGTCTG

CAGCACCTGGACGAACACC

CTACATGATCGTGTTGGTCTG

CTCTAACGAATGGACACGTAG

CATCAAGATGTTGGTGGTGG

CACTAAGCTGCAGTACTCGG

CATTACGCAGTGGAGTCCG

AGACACATATACTCTACATGG

CCTGCAAGATCTACAACTTCC

CTGGAGGAGAGGTTGTAGAG

CTACATGATCGTGTTGGTCTG

GGTTCACTTAACAGCTGGTG

ACCCAGATCATGTTCGAGACC ATGAGGTAGTCTGTGAGGTCG
Purpose

cDNA fragment generation

RACE

Full-length amplification

Probe preparation

Real-time PCR

Tissue distribution studies

$\beta$-actin amplification
Northern blot analysis of seabream tissues

A probe was prepared by labeling a fragment of the $s b G P R 39$ cDNA with a pair of primers (Table 1) using the PCR Dig Labeling System (Roche). Thirty micrograms of total RNA of each seabream tissue mixed with loading dye were denatured and separated on gel, transferred onto HybondN nylon paper (Northern Max-Gly kit, Ambion, Austin, TX, USA), and cross-linked by u.v. irradiation. Hybridization and detection were performed in accordance with the manufacturer's protocol. Briefly, after prehybridization at $42{ }^{\circ} \mathrm{C}$ for $4 \mathrm{~h}, 0.5 \mu \mathrm{l}$ of the probe was added and hybridization was performed overnight at $42{ }^{\circ} \mathrm{C}$. The blots were washed twice with washing buffer and non-specific binding sites were blocked by $1: 10000$ anti-Dig antibody. One milliliter of CDP-Star at 1:10 000 dilution was added to the membrane, and the chemiluminescent signal was then detected on a Syngene Bioimaging System (Synoptics, Cambridge, UK).

\section{Genomic organization of the GPR39 gene}

Seabream genomic DNA was isolated from the liver. Two pairs of primers used to confirm the ORFs of the two sbGPR 39 transcripts were used in the genomic PCR. The 
genomic PCR band was isolated and sequenced to compare with the cDNA sequences.

For species in which the genome sequence information is already available, a comparison of the cloned cDNA sequences with the genome sequences by BLASTwould yield information regarding the genomic organization of the GPR39 genes.

\section{Tissue distribution of GPR39 in seabream}

The expression profiles of two GPR 39 transcripts in seabream were analyzed by RT-PCR using gene-specific primers for the two receptors. The cDNA templates of different tissues from seabream were prepared as described above. Mock RT reactions without reverse transcriptase were used as negative controls for the reactions.

Two pairs of gene-specific primers differentiating sbGPR39-1a and sbGPR39-1b (Table 1) were employed to investigate the expression patterns of the two GPR39 transcripts. $\beta$-Actin was amplified in parallel to verify the integrity of all the cDNA samples. Five microliters of each reaction product were resolved on a $1.5 \%$ agarose gel containing ethidium bromide and visualized on a Gel Doc System (Bio-Rad). No contamination was found since all the negative controls gave no amplified products. The integrity of all the cDNA templates was verified by the successful and consistent amplification of the $\beta$-actin transcript.

\section{Cell culture, transfection, and functional assay}

Cell culture materials were purchased from Invitrogen. The HEK293 cell line was purchased from ATCC (Manassas, VA, USA). Cells were maintained at $37^{\circ} \mathrm{C}$ in DMEM containing $10 \%$ fetal bovine serum. All media were supplemented with antibiotics $(10 \mathrm{U} / \mathrm{ml}$ penicillin and $100 \mu \mathrm{g} / \mathrm{ml}$ streptomycin).

In the transfection experiments, Lipofectamine reagent (Invitrogen) was used. Twenty hours before transfection, $1.5 \times 10^{5}$ cells/well were seeded onto 24 -well tissue culture plates. Five hundred nanograms of the pSRE-Luc (Stratagene, La Jolla, CA, USA), 20 ng of pcDNA 4.0-sbGPR39-1a or pcDNA 4.0-sbGPR39-1b, and $50 \mathrm{ng}$ of pRL-CMV (for normalization of transfection efficiency) containing the Renilla luciferase reporter gene were co-transfected into the cells in $250 \mu \mathrm{l}$ serum-free medium. Six hours after transfection, the cells were incubated with $10 \mu \mathrm{M} \mathrm{ZnCl}$ or $0 \cdot 1 \mu \mathrm{M}$ human obestatin (ALEXIS Biochemicals, San Diego, CA, USA) for a further $20 \mathrm{~h}$. Luminescence was measured on a Lumat LB 9501 luminometer (EG \& G, Berthold, Bad Wildbad, Germany) and the activities of both luciferases were measured sequentially on the same sample.

Real-time PCR analysis of sbGPR39 and sbGHSR expression in seabream during food deprivation

Experimental design and tissue sampling Experimental fish were obtained from the Guangdong Daya Bay Fishery Development Center (Guangdong Province, China).
Forty black seabream of mixed sexes with body weight of $240 \pm$ $15 \mathrm{~g}$ were divided into two groups (20 fish per tank) and kept separately in $0.5 \mathrm{~m}^{3}$ indoor tanks supplied with constant seawater flow. Fish were fed once daily at a scheduled time (0900 h) with 3\% body weight of commercial diet. Fish were allowed to acclimatize to the feeding routine for 2 weeks. Feeding was abstained in one tank (food deprivation; FD), and fish in the other tank were fed as usual to serve as the control. Eight fish from each tank (control and FD groups) were anesthetized by immersing in 0.05\% MS222 solution and killed at 1100 h, 2 days, and 7 days after food withdrawal respectively. Tissues (hypothalamus and mid-intestine) were collected and immediately frozen in liquid nitrogen for later use.

Real-time PCR To monitor the expression levels of sbGPR 39 and sbGHSR in the tissues, real-time PCR was performed on an ABI PRISM 7900 Sequence Detection System (Applied Biosystems, Foster City, CA). One microgram of total RNA from each sample digested with DNase I was used as the template in the reverse transcription reaction. Real-time PCR was performed using the SYBR Green I kit (TOYOBO), according to the manufacturer's protocol. Standard curves for sbGPR39-1a, sbGPR39-1b, sbGHSR-1a, sbGHSR-1b, and $\beta$-actin were generated by serial dilutions of plasmid constructs of the target transcripts. Expression of $\beta$-actin was used as the internal control to correct for variations in template amount and RT efficiency. The primers used for each transcript are listed in Table 1. Real-time PCR was performed as described previously (Li et al. 2007). Fluorescent data were converted to threshold cycle $\left(C_{\mathrm{T}}\right)$ values (Livak \& Schmittgen 2001). The concentration of the template in the sample was determined by relating the $C_{\mathrm{T}}$ value to the standard curve. Transcripts levels were normalized against $\beta$-actin. Other studies have also reported on the use of $\beta$-actin as the internal control in gene expression studies in fish (Celius et al. 2000, Vong et al. 2003, Yada et al. 2005).

\section{Statistical analysis}

All data were expressed as the mean \pm s.E.M. from three or more independent measurements as indicated in the figure legends. Data were considered statistically significant at $P<0.05$ using either one-way ANOVA or unpaired $t$-test using the software Prism 4.0 (GraphPad Software, San Diego, CA, USA).

\section{Results}

\section{Isolation of two sbGPR39 transcripts from black seabream}

A fragment of sbGPR39 with a size of $343 \mathrm{bp}$ was isolated from seabream intestine using degenerate primers designed from the conserved regions of GPR39 in other species. A BLAST search indicates that the sequence of the isolated 
fragment is a putative GPR 39. According to the sequence information of the fragment, gene-specific primers were designed and employed in $5^{\prime}-$ and $3^{\prime}$-RACE reactions. Amplicons with a size of 1200 and $550 \mathrm{bp}$ from the $5^{\prime}-$ and $3^{\prime}$-RACE reactions respectively were cloned and sequenced. The RT-PCR and RACE fragments were assembled. Two primers designed at the $5^{\prime}-$ and $3^{\prime}$-untranslated regions (UTR) were used to confirm that the full-length cDNA sequence was correctly assembled. The full-length cDNA amplified from the seabream tissue was sequence confirmed and designated sbGPR 39-1a. The sbGPR 39-1a contains an ORF of $1272 \mathrm{bp}$ with a $5^{\prime}-\mathrm{UTR}$ of $254 \mathrm{bp}$ and a $3^{\prime}-\mathrm{UTR}$ of $449 \mathrm{bp}$. When translated, sbGPR39-1a encodes for a polypeptide of 423 aa, which shares $49 \cdot 9 \%, 47 \cdot 3 \%$, and $49 \cdot 6 \%$ in overall aa identity with the human, mouse, and chicken GPR39 respectively. Hydrophobicity analysis using the TMHMM program indicates sbGPR39-1a contains seven putative TM motifs (Fig. 3).

Another GPR39 transcript, designated sbGPR39-1b, was isolated from the seabream hypothalamus. 5'-RACE performed in the hypothalamus gave a band of identical size and sequence when compared with the $5^{\prime}$-RACE product from the intestine. A band of larger size $(700 \mathrm{bp})$ was obtained from the $3^{\prime}$-RACE reaction in the hypothalamus. The RT-PCR and RACE fragments were assembled to yield a complete cDNA sequence designated as sbGPR 39-1b consisting of an ORF of $852 \mathrm{bp}$, a $5^{\prime}$-UTR of $254 \mathrm{bp}$, and a $3^{\prime}$-UTR of $229 \mathrm{bp}$. Again gene-specific primers at the $5^{\prime}-$ and $3^{\prime}-\mathrm{UTR} s$ were used to confirm that the full-length $s b G P R 39-1 b \mathrm{cDNA}$ sequence was correctly assembled. As shown in Fig. 1,

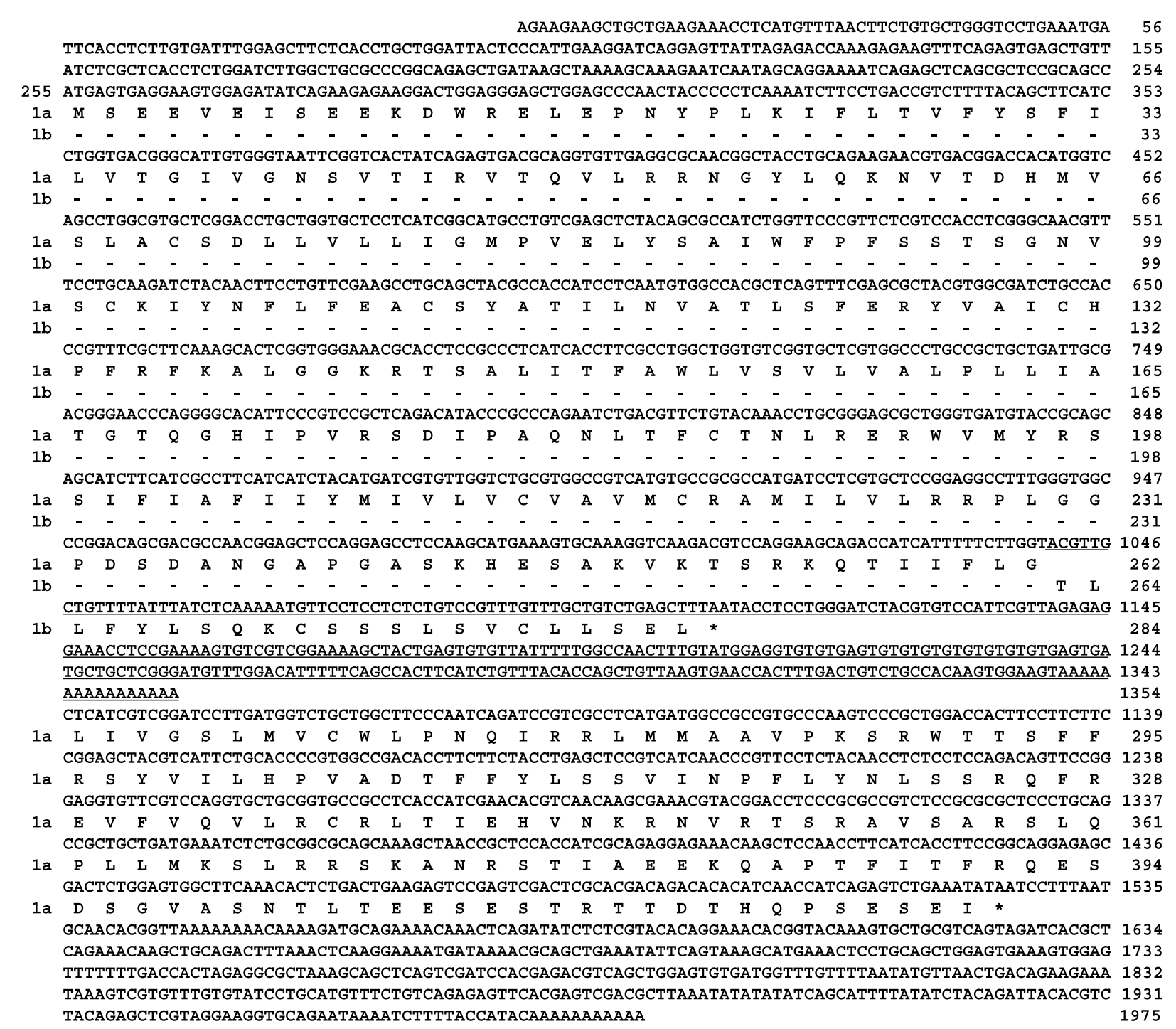

Figure 1 Nucleotide and deduced amino acid sequences of the sbGPR39-1a and sbGPR39-1b. Nucleotides (upper sequence) and amino acid (lower sequence) are numbered on the right-hand side. Identical sequences are shown as dashes. The stop codon (TAA) is indicated by asterisk, while the different nucleotide sequence of sbGPR39-1b is underlined. 
comparison of sbGPR39-1b with sbGPR39-1a revealed that the first $1040 \mathrm{bp}$, which encodes for the first 262 aa of the translated polypeptide, were the same. The sbGPR 39-1b ORF encodes for a polypeptide of 284 aa with five putative TM domains in the hydrophobicity analysis.

To further confirm that the two sbGPR39 transcripts indeed exist in seabream tissues, northern blot analysis was performed. Two bands of $\sim 2.0$ and $1.4 \mathrm{~kb}$ corresponding to the sizes of the cloned sbGPR 39 transcripts were detected in the intestine, stomach, and liver RNA samples (Fig. 5).

\section{Isolation of two GPR39 transcripts from other teleosts and} GPR39-1b from mammals

The presence of GPR39-1a and GPR39-1b transcripts in zebrafish and pufferfish was predicted in silico from the genome information, followed by experimental cloning of their complete ORFs using the primers described in Table 1. The presence of GPR 39-1b transcripts in human and mouse was also predicted in silico, followed by cloning of their complete ORFs. Hydrophobicity analyses indicate that all the GPR 39-1a sequences contain seven putative TM domains and all the GPR 39-1b sequences contain five putative TM domains.

Phylogenetic analysis was performed on the GPR39 sequences reported in the literature and those obtained in the present study, together with other members of the GHSR family. As shown in Fig. 4, GPR39 and GHSR were found to form separate related clades. The teleost GPR39 sequences obtained in the present study, although sharing less than $50 \%$ aa identity with the mammalian counterparts, do cluster together with the mammalian GPR39 sequences to form a phylogenetically distinct clade separate from the GHSR and GPR 38 sequences. The GHSR and GPR38 sequences appear to be more related to each other phylogenetically than to GPR 39 .

\section{GPR39 gene structure analysis}

The structures of the GPR 39 genes in human, mouse, zebrafish, and pufferfish were analyzed by comparison of the GPR39-1a cDNA sequence with the respective genome sequence. In all of these species, the GPR39 gene contains two exons and one intron, and the intron is located between TM5 and TM6. Comparison of the GPR39-1b cDNA sequence with the respective genome sequence in these species revealed that the GPR 39-1b cDNA sequence is identical to the respective genomic sequence corresponding to the first exon of GPR 39$1 \mathrm{a}$ and part of the $5^{\prime}$-end of the intron. Therefore, as shown in Fig. 2, two GPR39 transcripts could be generated by alternatively splicing the same gene. The GPR 39-1a transcript is generated by splicing away the intron and the GPR 39-1b transcript is generated by retaining part of the intron.

Using two primers flanking the ORF of sbGPR39-1b, a portion of the $s b G P R 39$ gene was amplified from the genomic DNA prepared from seabream tissue and sequenced. The nucleotide sequence of the amplified GPR39 genomic sequence was found to be identical to the $s b G P R 39-1 b c D N A$

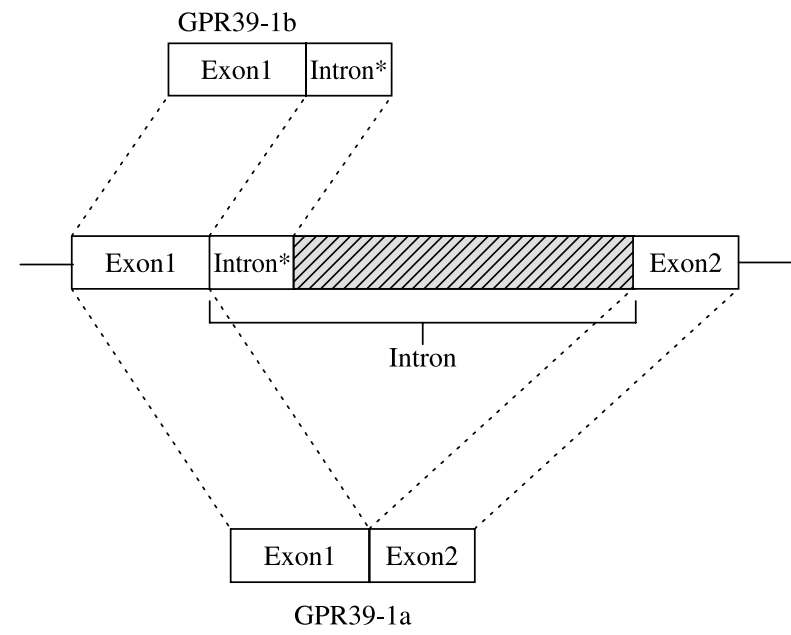

Intron* refers to part of intron

Figure 2 Schematic representation of the vertebrate GPR39 gene and alternative splicing mechanism. The GPR39 gene contains two exons and one intron. The two GPR39 transcripts are generated by removing the intron or retaining part of it.

sequence. It appears therefore that the scheme proposed in Fig. 2 is conserved in all the species that we have studied in the present study from mammals to teleosts (Figs 3-5).

\section{Tissue expression patterns of the two sbGPR39 transcripts in} seabream

The expression profiles of the two GPR39 transcripts in different seabream tissues were investigated by RT-PCR. As shown in Fig. 6, sbGPR39-1a mRNA was found to be abundantly expressed in the gastrointestinal tract, liver, adipose tissue, and kidney. Some expression of the sbGPR 39-1a transcript was also detected in the midbrain and testis. However, sbGPR39-1a expression was very low or virtually undetectable in most brain regions.

Different from the expression pattern of sbGPR39-1a, which is confined to a relatively small number of tissues, the $s b$ GPR 39-1b mRNA was found to be expressed in all the tissues examined except muscle and ovary. In the brain regions, high sbGPR 39-1b expression was found in the midbrain, hindbrain, and medulla. Appreciable expression was also detected in the other brain regions such as the forebrain, pituitary, and hypothalamus. In the peripheral organs, sbGPR 39-1b was found to be expressed predominantly in the gastrointestinal tract, liver, and kidney where sbGPR39-1a is also expressed abundantly. Therefore, co-expression of sbGPR 39-1a and sbGPR 39-1b is evident in these peripheral tissues.

\section{Expression of the two cloned sbGPR39 receptors in cultured cells}

As shown in Fig. 7, when the sbGPR39-1a receptor was transfected into HEK293 cells in culture, $\mathrm{Zn}^{2+}$ at $10 \mu \mathrm{M}$ could trigger the SRE signaling pathway, as indicated by the induction 


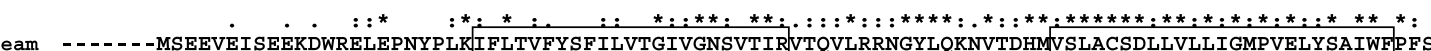
seabream -- - -MSEEVEISEEKDWRELEPNYPLKIFLTVFYSFILVTGIVGNSVTIRVTQVLRRNGYLQKNVTDHMVSLACSDLLVLLIGMPVELYSAIWFPFS pufferfish - - - - - MSEEAELPDEKDWRELEPHYPVKIFLTLLYSLMLLTGIVGNAVTIRVSQVLKQNGYLQKNVTDHMISLACSDLLVLLIGMPVELYSAIWFPFT zebrafish - - - - - MDPQQP - ERDWQQLEPSYGLKVFLTVLYCLILSLGVLGNSATIHVAQVLQRNGYLQRSVAEHMVSLACSDLLVLLIGLPVELYSAIWFP FI

chicken MAGQT-SSSDCSHLIDHSHISEFEVSPWIKITLALLDICIFVAGILGNSITIKATRILQKKGYLQKEVTDHMVSLACSDLLVILLGMPVEFFSAIWKPFA mouse MASSSGSNHICSRVIDHSHVPEFEVATWIKITLILVYLIIFVVGILGNSVTIRVTOVLOKKGYLOKEVTDHMVSLACSDILVFLIGMPMEFYSIIWNPLT human MASPSLPGSDCSQIIDHSHVPEFEVATWIKITLILVYLIIFVMGLLGNSATIRVTQVLQKKGYLQKEVTDHMVSLACSDILVFLIGMPMEFYSIIWNPLT TM-1

TM-2

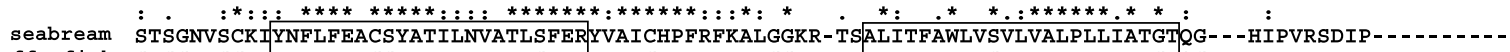
pufferfish SASGNVSCKIYNFLFEACSYATIVNIATLSFERYVAICHPFRYKALGGKR - TNALIAFAWLVSVLVALPLLIATGTQG - - -HIPLRADTP - - - - - - - zebrafish SRSGDAACRIYNFLFELCSYATILNVATLSFERYLAICHPFRYRALRGGR - TRRLLLAAWLCSALVALPLLVATGTEG - - - YVPAGROTP - - - - - - - -

chicken TPNGNVACKI YYFLFEACSYATVLHVATLSFERYVAICHPFKFKAVSGPRKVKILIAFVWGTSVIVALPLLFAMGTEYPLEIIENYOGVTACAKSTARHH mouse TPSYALSCKI HTFLFETCSYATLLHVLTLSFERYIAICHPFKYKAVSGPRQVKLLIGFVWVTSALVALPLLFAMGIEYPLVNVPTHKGLN-CNLSRTRHH $\begin{array}{ll}\text { mouse } & \text { TPSYALSCKL HTLFETCSYATLLHVLTLSFERYIAICHPFKYKAVSGPRQVKLLIGFVWVTSALVALPLLFAMGIEYPLVNVPTHKGLN - CNLSRTRHH } \\ \text { human TSSYTLSCKLHTFLFEACSYATLLHVLTLSFERYIAICHPFRYKAVSGPCQVKLLIGFVWVTSALVALPLLFAMGTEYPLVNVPSHRGLT-CNRSSTRHH }\end{array}$ TM-3 TM-4

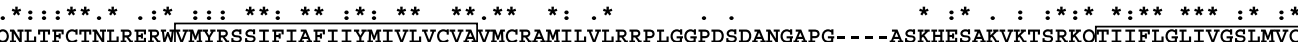

seabream pufferfish zebrafish

chicken

mouse human seabream
pufferfish zebrafish

chicken

mouse

human

seabream : $\quad$ : औ * pufferfish

zebrafish

chicken

mouse
human

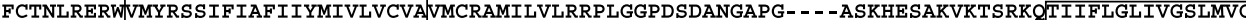
作 - - - VQNLTFCTSLSQHWVMYRTSIFTAFVLYLLVLAGVAFMCRAMILVLRAPMGPAEAGASGDH - - - - - - -KHQSARGKASRKQTILFLGLIVCALFVC LPELKQNMTICTSLSSKWPVFQASIFSAFAVYIIVLGSVAFMCRSMMKTLMIHKKGTVAVKGEPGQQEQYLRKSESSEGKSSRRQIILFLGLIVATLAIC DEPGNSNMSICTNLSNRWEVFQS IFGAFAVYLVVLASVAFMCWNMMKVLMKSKQGTLAGTGPQLQ- - - LRKSESEESRTARRQTIIFLRLIVVTLAVC EOPETSNMS ICTNLSSRWTVFOSSIFGAFVVYLVVLLSVAFMCWNMMOVLMKSOKGSLAGGTRPPO - _ - LRKSESEESRTARROTIIFLRLIVVTLAVC TM-5 TM-6

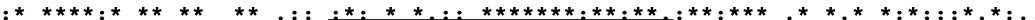
**: WLPNOTRRLMMAAVPKSRWTTSFFR SYVILHPVADTFFYLSSVINPFLYNLSSROFREVFVOVLRCRLTIEHVNKRN- - -VRTSRAVSAR - -SLQPLLMK WLPMQI RRVMMAALPKSSWTASFFR SYVILQPVADTFFYLSSVINPFLYNLSSRQFREVFVQVLRCRLTIQHVNKRT - - -VPAAAHVTSR - - SLRPLLRWMPNQIRRLMTAAVPKSSWTGSYLTSYIKLHPVADSFFYLSSVLNPML YNLSSRQFRSAFLQTLLCRLSLQHANRRT - - - LENSGASKSSNNTLRPLLQR WMPNOI RRIMAAAKPKODWTVPYFR AYIILLPIADIFFYLSSVVNPLLYNISSOQFRSVFLOVLRCHLTIEHANKEKFLRANLSSRARSSRSLR - PLLFI WMPNQIRRIMAAAKPKHDWTRTYFRAYMILLPFSDTFFYLSSVVNPLLYNVSSQQFRKVFWQVLCCRLTLQHANQEKRQRARFISTKDSTSSARSPLIFL WMPNQIRRIMAAAKPKHDWTRSYFRAYMILLPFSETFFYLSSVINPLLYTVSSQQFRRVFVQVLCCRLSLQHANHEKRLRVHAHSTTDSARFVQRPLLFA

\section{TM-7}

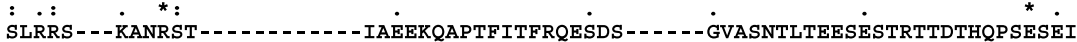
SLRRN - - TDMRSN- - - - - - - - KAEEAVP - - - SVQVEDDS - . - - -GIASLSKMEESKTTLOTADIO-SESDV SLNRIRMATSSRSTPPSSAERRDSLNTTDRPOGEGKLTLDPONTTNWPOGEGELTSDSOEKERNOLTHCPTLPDEOSS

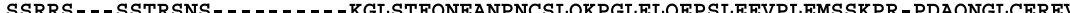

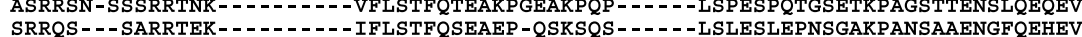

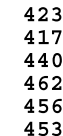

Figure 3 Multiple alignment of GPR39-1a amino acid sequences. Sequences were aligned by the CLUSTAL_X program. Identical sequences are indicated by asterisks. The TM domains are indicated. Gaps (indicated by hyphens) are introduced in some sequences to maximize alignment.

of luciferase activity of the reporter gene. On the other hand, however, transfected HEK293 cells bearing the sbGPR39-1b receptor could not be stimulated by $\mathrm{Zn}^{2+}$. Also, in line with the findings that obestatin is unable to activate the GPR 39 receptor, our attempts to stimulate the sbGPR39-1a and sbGPR39-1b receptors with this peptide failed to detect any bioactivity.

\section{Effect of FD on sbGPR39 and sbGHSR expression in seabream}

The expression patterns of sbGPR 39 and sbGHSR during FD in seabream were investigated by real-time PCR. As shown in Fig. 8, after 2 days of FD, the expression level of sbGPR39-1a was somewhat lowered in the mid-intestine when compared with the control. This decrease became significant after 7 days of FD, with the sbGRP39-1a level decreased to less than 50\% of the control level (Fig. 8A). However, the expression level of sbGPR 39-1b was not significantly changed in the mid-intestine after FD (Fig. 8B). On the contrary, the expression level of sbGPR 39-1b was significantly decreased in the hypothalamus after 7 days of FD (Fig. 8C). The sbGHSR-1a expression level was increased sharply in the hypothalamus after 2 days of FD. After 7 days of FD, this increase was enhanced even more (Fig. 8D). Similar to that of sbGHSR-1a, the expression level of sbGHSR-1b was also significantly increased in the hypothalamus after FD (Fig. 8E).

\section{Discussion}

Sequence and phylogenetic analysis of GPR39

GPR39 is a GPCR belonging to the ghrelin receptor subfamily (McKee et al. 1997). We have cloned and characterized ghrelin and ghrelin receptor in black seabream previously (Chan \& Cheng 2004, Yeung et al. 2006). In the present study, we report the identification and characterization of another ghrelin receptor family member, namely sbGPR39-1a and sbGPR39-1b, from the same organism.

Several characteristics of the cloned sbGPR39-1a sequence revealed that it is an ortholog of the GPR39 identified in avian and mammalian species. Apart from the characteristic feature of possessing seven putative TM domains, the SXXNPXXY motif in TM7 and the D(E)-R-Y(F) motif at the end of TM3, both of which are landmarks of the rhodopsin family members, are also found in sbGPR39-1a. The aa sequences of the two cytoplasmic loops between TM1 and TM2, and between TM3 and TM4, as well as an extracellular loop between TM6 and TM7, are highly conserved (Fig. 2). In addition, phylogenetic analysis revealed that GPR 39 formed one separate clade distinct from the other GHSR receptor family members. These findings suggest that GPR39 is structurally conserved among different species. 

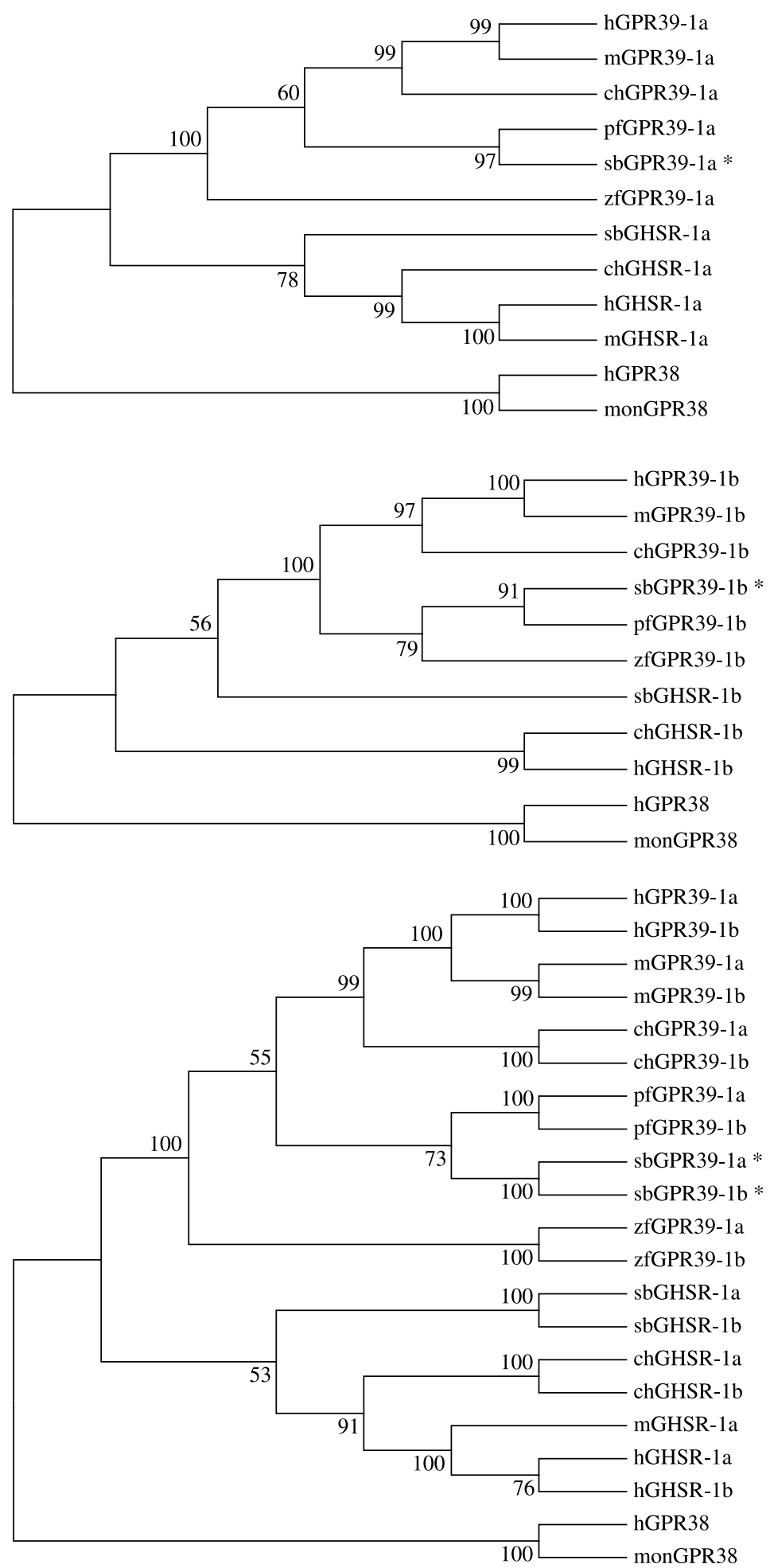
Identification of an additional GPR39-1b transcript among various vertebrates

A careful examination of the mRNA expression of GPR39 in the seabream hypothalamus has led us to the identification of another GPR 39 transcript in seabream. Two pairs of primers flanking different regions of sbGPR39-1a were initially employed in preliminary experiments to determine whether GPR39 is expressed in the hypothalamus. Interestingly, expression of sbGPR39-1a was clearly detected in the hypothalamus using one pair of primer flanking the $5^{\prime}$ UTR and TM2. However, another pair of primer (sbGPR39-1a $\mathrm{F}$ and sbGPR39-1a R) flanking TM4 and TM7 failed to detect GPR 39 expression in the hypothalamus. Based on this observation, we hypothesized that another transcript of GPR 39, which shares the same region with the isolated sbGPR 39-1a at the $5^{\prime}$-end, is exclusively expressed in the hypothalamus. Therefore, $3^{\prime}$-RACE were performed using the seabream hypothalamus as the template. The sbGPR 39-1b transcript was subsequently isolated from the hypothalamus. By northern blot analysis, we confirmed that two GPR 39 transcripts indeed exist in seabream tissues.

The cDNA sequences of GPR39 have been reported in human, rat, mouse, and, more recently, in chicken (McKee et al. 1997, Zhang et al. 2005, Yamamoto et al. 2007). In the present study, we have clearly demonstrated the presence of two alternatively spliced forms of GPR 39 in teleosts as well as in mammals, and that these two receptors in seabream are distinct in biological function and are differentially expressed. During the preparation of this manuscript, Egerod et al. (2007) also reported that GPR39-1b transcripts are found in human, mouse, rat, and chicken, further supporting the notion that the presence of two GPR 39 transcripts is a general phenomenon among vertebrates.

\section{The structure of the GPR39 gene}

The structures of the mammalian and teleostean GPR39 genes containing two exons and one intron were shown to be similar to that in chicken. The position of the intron, located between TM5 and TM6, is also conserved among these species. This observation suggests that the gene structure of GPR39 is evolutionarily conserved from teleost to human. Despite our repeated trials, attempts to isolate the whole intron of the $s b G P R 39$ gene in seabream were unsuccessful. This was probably due to the large size of the intron in seabream. In this context, it should be noted that the intron is about $61 \mathrm{~kb}$ in the chicken gene, and even in the more compact genome of pufferfish, this intron is more than $4.5 \mathrm{~kb}$ in size.

Comparison of the two GPR39 transcripts with the genomic sequence revealed that alternative splicing of the same gene may give rise to the two GPR 39 transcripts in human, mouse, zebrafish, and pufferfish. In one situation, if the intron is removed, it will generate a long-form receptor with seven TM motifs. In another situation, if the intron is not spliced away completely, it will generate a truncated receptor with only five TM domains (Fig. 2). The presence of an inadvertent stop codon in the intron sequence retained in the mRNA is responsible for the generation of the truncated receptor form. A very similar situation was observed for the generation of the two GHSR transcripts (Howard et al. 1996, Chan \& Cheng 2004) and the two motilin receptor transcripts (Feighner et al. 1999). The occurrence of two alternatively spliced forms of the same receptor gene appears to be a common phenomenon in the ghrelin receptor family. Although the whole intron of the $s b G P R 39$ gene has not been isolated, we have demonstrated that the sbGPR 39-1b sequence, the same as that seen in human and mouse, was identical to the genomic sequence. This observation suggests that sbGPR 39-1b is probably generated in a fashion similar to that in humans and mice. The conserved gene structure, together with a partial sequence of the sbGPR39 gene determined, indicates that two sbGPR39 transcripts are probably generated by alternative splicing of the GPR 39 gene in seabream.

\section{Tissue distribution of GPR39 transcripts in seabream}

Study on the expression pattern of GPR 39 may shed light on the physiological roles of the receptor. In some aspects, the expression pattern of GPR 39-1a in seabream is similar to that reported in human and chicken where the gastrointestinal tract is the primary site of expression (Zhang et al. 2005, Nogueiras et al. 2007, Yamamoto et al. 2007). The high expression in the gastrointestinal tract suggests that GPR 39 might be involved in regulating gut functions. Consistent with this notion, the volume of gastric secretion was increased and gastric emptying accelerated in GPR 39 knockout mice (Moechars et al. 2006). A previous report has also demonstrated that GPR39-1a is expressed in the hypothalamus and pituitary of mammals (Zhang et al. 2005). On

Figure 4 Phylogenetic analysis of the amino acid sequences of GPR39, GPR38, and GHSR from different vertebrates. Phylogenetic analyses were performed using MEGA3.1 by the maximum parsimony method with 1000 bootstrap replicates. The sbGPR39-1a and sbGPR39-1b are highlighted by asterisks. The GPR39, GPR38, and GHSR sequences used in the analysis and their GenBank accession numbers are: black seabream (Acanthopagrus schlegelii) sbGHSR-1a AAN77875 and sbGHSR-1b AAN77876; chicken (Gallus gallus) chGHSR-1a BAC76445, chGHSR-1b BAC76446, and chGPR39-1a ABG75918; human (Homo sapiens) hGHSR-1a NP_940799, hGHSR-1b NP_004113, hGPR38 O43193, and hGPR39-1a AAI25047; mouse (Mus musculus) mGHSR-1a Q99P50 and mGPR39-1a AAH85285; and monkey (Macaca mulatta) monGPR38 XP_001101857, together with the sequences obtained in the present study: black seabream (Acanthopagrus schlegelii) sbGPR39-1a EU076425 and sbGPR39-1b EU076426; zebrafish (Danio rerio) zfGPR39-1a EU076427 and zfGPR39-1b EU076428; pufferfish (Takifugu rubripes) sbGPR39-1a EU076429 and sbGPR39-1b EU076430; human (Homo sapiens) hGPR39-1b EU076432; and mouse (Mus musculus) mGPR39-1b EU076431. 


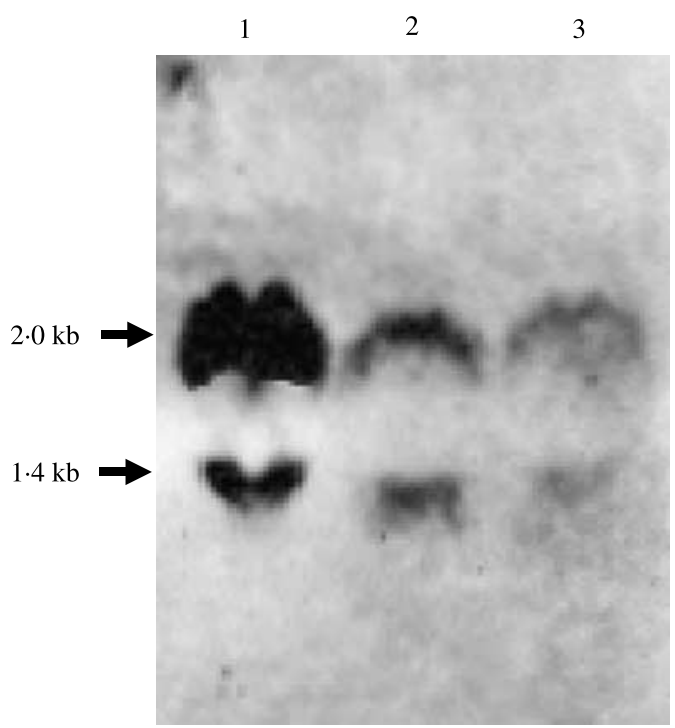

Figure 5 Northern blot analysis of the two sbGPR39 transcripts in seabream. Thirty micrograms of total RNA were isolated from the intestine (lane 1), stomach (lane 2), and liver (lane 3). Two bands of $\sim 2.0$ and $1.4 \mathrm{~kb}$ in sizes were detected in the mRNA samples.

the contrary, we did not detect any expression of GPR 39-1a in the seabream hypothalamus and pituitary even using 40 cycles of PCR amplification. In fact, several other groups also failed to detect GPR39-1a expression in the hypothalamus using RT-PCR or in situ hybridization (Jackson et al. 2006, Holst et al. 2007, Nogueiras et al. 2007). The absence of sbGPR39-1a in the hypothalamus and pituitary probably suggests a relatively unimportant role of this receptor in modulating pituitary hormone release. However, the presence of sbGPR 39-1a in other brain regions may imply that this receptor might be involved in some other yet unidentified neural functions. Interestingly, both sbGPR39$1 \mathrm{a}$ and sbGPR 39-1b are abundantly expressed in many tissues such as the gastrointestinal tract, liver, and kidney. The

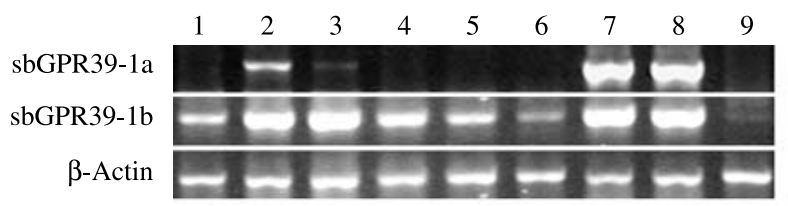

\begin{tabular}{|c|c|c|c|c|c|c|c|c|c|}
\hline & 10 & 11 & 12 & 13 & 14 & 15 & 16 & 17 & 18 \\
\hline sbGPR39-1a & $\Rightarrow$ & - & & $E$ & & 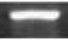 & $=$ & & \\
\hline sbGPR39-1b & 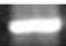 & $=$ & & 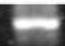 & $=$ & 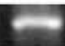 & 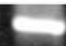 & - & \\
\hline$\beta$-Actin & $=$ & $\Rightarrow$ & $=$ & $=$ & $=$ & $=$ & $\Rightarrow$ & $=$ & \\
\hline
\end{tabular}

Figure 6 Analysis of GPR39-1a and GPR39-1b mRNA expression in seabream tissues by RT-PCR. The different tissues are: 1 , forebrain; 2 , midbrain; 3 , hindbrain; 4, medulla; 5 , pituitary; 6 , hypothalamus; 7, intestine; 8 , stomach; 9 , muscle; 10 , liver; 11 , testis; 12 , ovary; 13, gill filament; 14 , heart; 15 , adipose tissue; 16 , kidney; 17 , spleen; 18 , negative control. co-expression of the two GPR39 transcripts in peripheral regions might imply functional interaction between each other. However, sbGPR 39-1b is also expressed in other tissues where there is little sbGPR39-1a, particularly in the brain regions including the hypothalamus and pituitary. A similar tissue expression pattern of GPR 39-1b in mouse was reported by Egerod et al. (2007). This conserved GPR39-1b expression pattern in mammals and fish implies a possible physiological role of the truncated receptor in these tissues.

What factors, transcriptional or otherwise, that control the differential expression of the two alternatively spliced receptors in seabream tissues are not known at the moment. Whether there is alternative promoter usage of the $5^{\prime}$-flanking region of the single GPR39 gene is an interesting and worthwhile follow-up study.

\section{Functional study of the two sbGPR39 transcripts}

Despite the fact that the endogenous ligand for GPR39 is still unknown, previous studies have indicated that $\mathrm{Zn}^{2+}$ could activate human GPR39 in HEK293 cells (Holst et al. 2004, 2007, Lauwers et al. 2006). In the present study, we have also observed that $\mathrm{Zn}^{2+}$ is capable of triggering sbGPR39-1a signaling via the SRE pathway. In line with the findings of Zhang et al. (2007), the obestatin peptide was totally inactive in this regard. This observation suggests that GPR39 is functionally conserved during evolution. Therefore, GPR 39 may serve important physiological functions in phylogenetically diversified species. However, the physiological roles and signaling pathways cannot be fully unraveled until the natural ligand for GPR39 becomes known.

It appears from our results that sbGPR 39-1b is a truncated receptor devoid of signaling ability. However, the unavailability of the natural ligand for GPR 39 has hampered us to test this assumption. At this juncture, it is interesting to note the occurrence of a similar situation in another receptor of the same family in seabream. We have previously reported that sbGHSR-1b, a truncated receptor form of the functional ghrelin receptor in seabream, is incapable of signal transduction (Chan \& Cheng 2004). A comparison of the truncated receptor sbGPR 39-1b with the functional sbGPR 39-1a revealed that the main discrepancy between them lies on the topology architecture: the truncated receptor contains five TM domains and the functional one has seven TM domains. Therefore, the lacking of TM6 and TM7 in the truncated receptor may be responsible for its dysfunction. According to the global toggle switch model, activation of seven TM receptors requires an inward movement of TM6 and TM7 toward the inner face of TM3 (Schwartz et al. 2006). Consistent with this view, it is interesting to note that truncated chemokine receptors with five TM motifs lacking TM1 and TM2 act as fully functional GPCRs (Ling et al. 1999). Moreover, receptor mutation analysis of GHSR and GPR39 indicates that TM6 and TM7 are essential for the constitutive receptor activity, further supporting the hypothesis that lacking in TM6 and TM7 


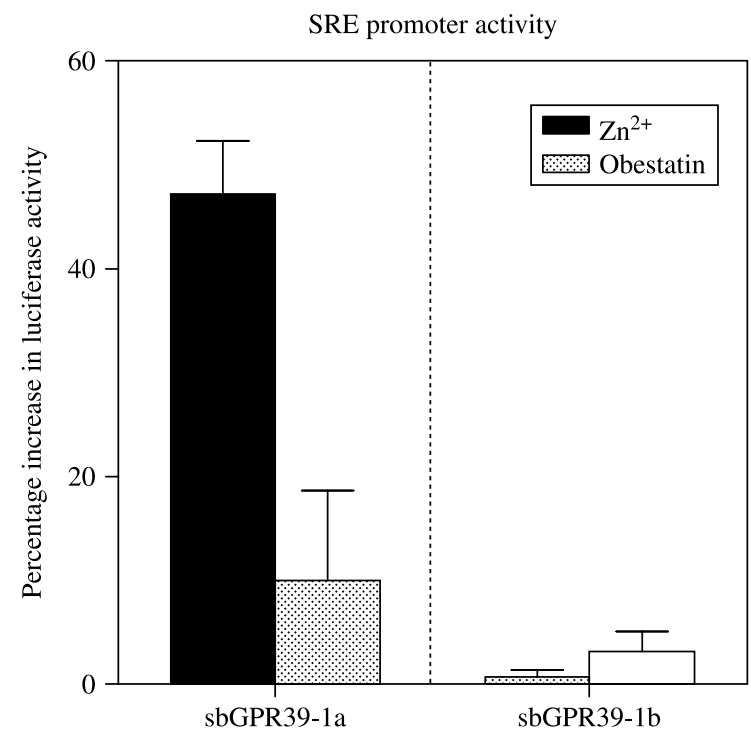

Figure 7 Effects of $\mathrm{Zn}^{2+}$ and human obestatin on SRE reporter activity in HEK293 cells transfected with sbGPR39-1a and sbGPR39-1b. In each experiment, cells were incubated with $10 \mu \mathrm{M}$ $\mathrm{Zn}^{2+}$ or $0 \cdot 1 \mu \mathrm{M}$ human obestatin in triplicate wells for $20 \mathrm{~h}$. Values are the means \pm S.E.M. from three independent experiments, expressed as the percentage increase in luciferase activity above the control (without any stimulating agent).

has led to the inability of the truncated receptors in activating the signaling events (Holst et al. 2004).

\section{Effect of FD on sbGPR39 and sbGHSR expression in seabream}

Since GPR 39 is expressed mainly in the gastrointestinal tract and GPR39 is a member of GHSR receptor family, which plays important roles in regulating food intake and energy homeostasis (Kojima \& Kangawa 2005), we have therefore investigated the gene expression of GPR39 and GHSR during FD in seabream. Our observation that there is a drastic elevation in the gene expression of the GHSR-1a receptor in the hypothalamus of the seabream during FD agrees with the results of a previous study conducted in rats (Kim et al. 2003). In addition, we have also observed a concomitant decrease in the expression of the sbGPR39-1a receptor in the seabream intestine during food derivation in the present study. Interestingly, during the course of preparing this manuscript, Egerod et al. (2007) reported that GPR39-1a mRNA level was upregulated in adipose tissue upon fasting and downregulated during adipocyte differentiation in rats. Taken together, these data suggest that GPR39 and GHSR gene expression is highly responsive to metabolic signals related to the fed-fast states of the animals, and that the reciprocal regulatory nature of the two receptors appear to be conserved from teleosts to mammals.

The remarkable changes in the expression levels of GPR 39 and GHSR may have important physiological bearings. Holst et al. (2003) have shown that the constitutive signaling activity of GHSR can reach $50 \%$ of the maximal signaling efficiency evoked by its natural ligand ghrelin. Similar to GHSR, GPR 39 is also a constitutively active receptor signaling mainly through the SRE pathway (Holst et al. 2004). We have also observed that the sbGHSR-1a receptor in seabream is a constitutively active receptor (Chan et al. 2004). The high ligand-independent constitutive signaling activity implies that changes in receptor expression are directly connected with the signaling and therefore physiological events. Thus, a change in receptor gene expression under different energy status would directly influence the constitutive signaling activities of the receptors. It has been suggested that the high basal signaling activity of GHSR-1a may provide a set point to act against inhibitory signals from the anorexigenic peptides such as leptin, insulin, and PYY3-36 (Holst \& Schwartz 2004). Therefore, the significant increase in GHSR expression after FD could be interpreted as a demand for more stimulatory signals for food intake and less energy expenditure. Interestingly, natural mutations of the GHSR-1a receptor in human, Ala204Glu and Phe279Leu, leading to the loss of the constitutive signaling activity have been associated with short stature and obese phenotype (Wang et al. 2004, Pantel et al. 2006). These findings suggest that the constitutive signaling activity of the GHSR-1a is normally needed and dramatic changes in the mRNA levels of GHSR-1a have significant physiological consequence. On the other hand, however, the significance of the constitutive signaling activity of GPR 39 is not clear. The concomitant and reciprocal expression patterns of GHSR and GPR 39 after FD strongly suggest that these two receptors possess opposing roles in controlling food intake and energy homeostasis.

\section{FD influences sbGPR39 and sbGHSR expression}

It has been recognized that truncated GPCRs, generated by alternative splicing of GPCR transcripts, may modulate the function of the full-length 7 TM version of the receptor by influencing its expression, ligand binding properties, and cellular location (Karpa et al. 2000, Nakamura et al. 2004, McElvaine \& Mayo 2006, Beaumont et al. 2007). We have previously reported that the truncated $s b G H S R-1 b$ receptor can modulate the sbGHSR-1a receptor signal transduction activities (Chan \& Cheng 2004). Further investigations have demonstrated that the GHSR $-1 \mathrm{~b}$ receptor can attenuate the constitutive signaling activity of the GHSR-1a receptor by forming a heterodimer between GHSR-1a and GHSR-1b (Chu et al. 2007, Leung et al. 2007). Therefore, GHSR-1b acts as a dominant-negative mutant of the full-length receptor. How physiological status influences the expression of these receptor variants, and thus their dimerizaton, is largely unknown. Our results revealed that the expression of both sbGHSR-1a and sbGHSR-1b is increased after FD. Thus, the overall effect would represent a change in receptor signaling events responding to the negative energy balance. The concomitant increase of the $1 \mathrm{~b}$ form in this case might 

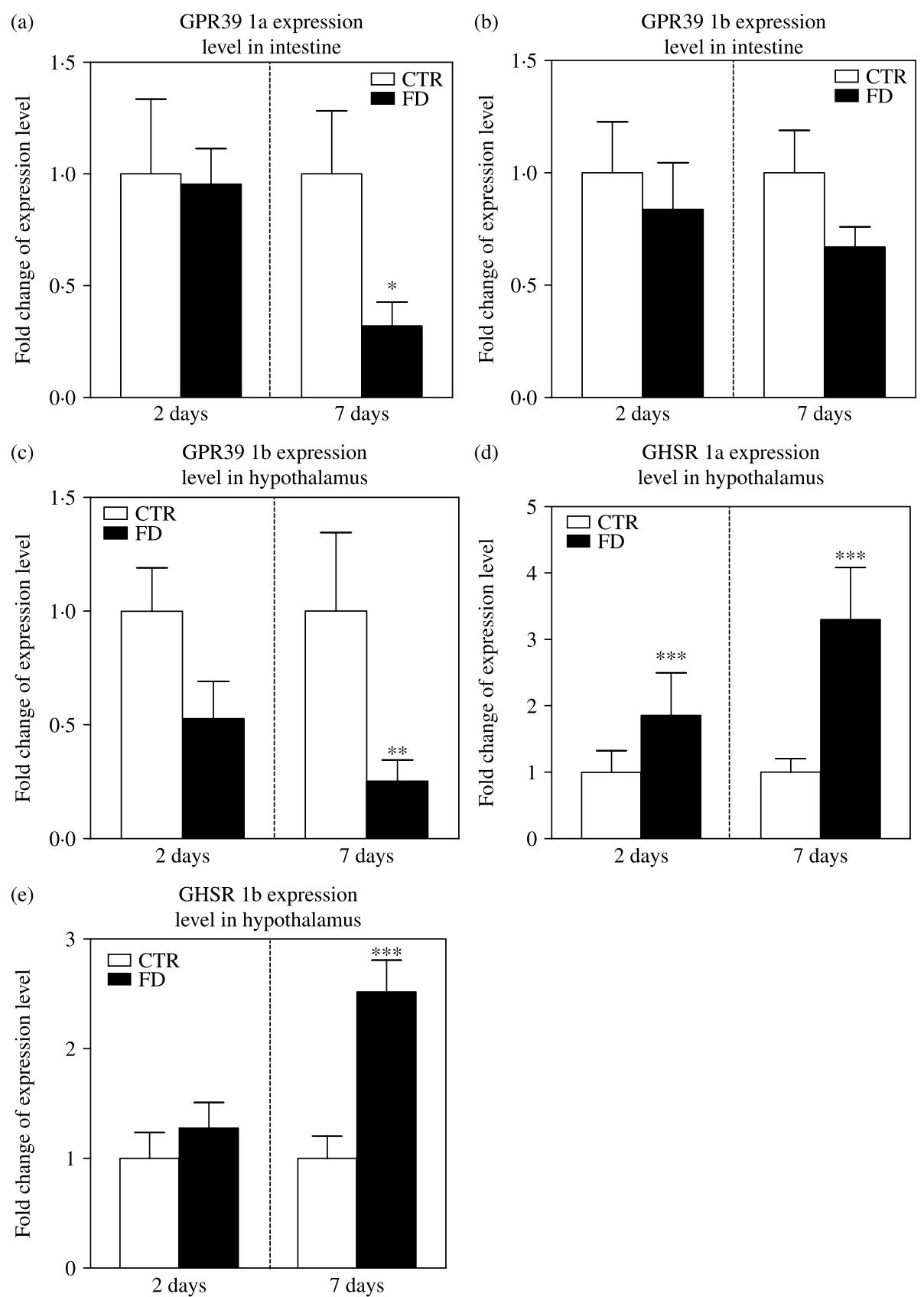

Figure 8 Real-time PCR analysis of relative mRNA levels of $s b G P R 39-1 a, s b G P R 39-1 b, s b G H S R-1 a$, and $s b G H S R-1 b$ of food-deprived (FD) seabreams. Seabreams were food deprived for 2 and 7 days. The relative mRNA levels of (A) sbGPR39-1a in the mid-intestine, (B and C) $s b G P R 39-1 b$ in the midintestine and hypothalamus, and (D and E) $s b G H S R-1 a$ and $s b G H S R-1 b$ in the hypothalamus were measured by real-time PCR. Results are expressed as mean \pm s.E.M. $(n=8) .{ }^{*} P<0 \cdot 05,{ }^{* *} P<0 \cdot 01$, $* * * P<0 \cdot 001$ versus the respective controls $(\mathrm{CTR})$.

act as a self-limiting process to mitigate the action of the increased $1 \mathrm{a}$ form.

GPR 39-1b is also a truncated receptor form, which shares much in common with GHSR-1b: a wide distribution pattern, 5 TM topology architecture and the apparent lack of signaling activity. Given such similarities between GPR39-1b and GHSR-1b and a natural tendency to form oligomers among the GPCR family members (Woolf \& Linderman 2003), a putative role for GPR 39-1b could also be to act as a modulator of GPR39-1a constitutive signaling activity by 
forming heterodimers, particularly in view of the fact that the $1 \mathrm{a}$ and $1 \mathrm{~b}$ receptors are co-expressed in some of the central and peripheral tissues in seabream. Our results revealed that the expression of both GPR 39 transcripts in the mid-intestine appeared to be decreased after FD, although the decrease in the $1 \mathrm{~b}$ form did not reach statistical significant level within the period of study. If heterodimerization between the two GPR39 variants does occur, the overall effect would be envisaged to represent a composite change in receptor signaling events in response to the negative energy balance. Interestingly, the expression of sbGPR 39-1b was also decreased in the hypothalamus after FD, suggesting some other functional role of GPR 39-1b in some brain regions that do not normally express GPR39-1a. Another possible role for GPR 39-1b could be to act as a scavenger receptor that influences ligand transportation or internalization, which was previously reported in a subfamily of GPCRs that interact with chemokines (Bonecchi et al. 2004).

\section{Evolution of the ghrelin receptor family}

GPR39 is an orphan receptor of the ghrelin receptor family. GPR39, GHSR and GPR38 share many common characteristics: from their gene structure, generation of receptor subtypes, to their responsiveness toward metabolic signals. However, each receptor has its own characteristic properties. For example, GPR39 and GPR38 are most abundantly expressed in the gastrointestinal tract while GHSR is most abundantly expressed in the brain. On the other hand, GPR39 and GHSR exhibit substantial ligand-independent constitutive signaling activities while GPR38 is devoid of such activity. These observations suggested that GPR39, GHSR and GPR38 might be derived from a common ancestral gene but have been functionally differentiated during evolution. Although differences have been accumulated during receptor evolution, they are all involved in some kind of metabolic regulation process, which might represent the ancient function of the common ancestral gene. If this hypothesis is valid, this differentiation must have occurred a long time ago before the divergence of vertebrates, as many of the characteristics and functionalities in these receptors are respectively conserved during the course of vertebrate evolution over a period of $\approx 400$ million years from teleost fish to modern mammals.

\section{Declaration of interest}

The authors declare that there is no conflict of interest that would prejudice the impartiality of this scientific work.

\section{Funding}

The following granting agencies are gratefully acknowledged: the Hi-Tech Research and Development Program of China 863 Projects (No. 2006AA10A402) and the National Key Technology Research and
Development Program (2006BAD09A14 and 2007BAD29B01). We also thank the Research Grants Council of the Hong Kong Special Administrative Region (no. CUHK4149/01M) and the United College Visiting Scholar Scheme (to Dr Yong Zhang).

\section{References}

Beaumont KA, Shekar SN, Newton RA, James MR, Stow JL, Duffy DL \& Sturm RA 2007 Receptor function, dominant negative activity and phenotype correlations for MC1R variant alleles. Human Molecular Genetics 16 2249-2260.

Bonecchi R, Locati M, Galliera E, Vulcano M, Sironi M, Fra AM, Gobbi M, Vecchi A, Sozzani S, Haribabu B et al. 2004 Differential recognition and scavenging of native and truncated macrophage-derived chemokine (macrophage-derived chemokine/CC chemokine ligand 22) by the D6 decoy receptor. Journal of Immunology 172 4972-4976.

Celius T, Matthews JB, Giesy JP \& Zacharewski TR 2000 Quantification of rainbow trout (Oncorhynchus mykiss) zona radiata and vitellogenin mRNA levels using real-time PCR after in vivo treatment with estradiol-17 $\beta$ or $\alpha$-zearalenol. Journal of Steroid Biochemistry and Molecular Biology 75 109-119.

Chan CB \& Cheng CHK 2004 Identification and functional characterization of two alternatively spliced growth hormone secretagogue receptor transcripts from the pituitary of black seabream Acanthopagrus schlegeli. Molecular and Cellular Endocrinology 214 81-95.

Chan CB, Leung PK, Wise H \& Cheng CHK 2004 Signal transduction mechanism of the seabream growth hormone secretagogue receptor. FEBS Letters $\mathbf{5 7 7} 147-153$.

Chartrel N, Alvear-Perez R, Leprince J, Iturrioz X, Reaux-Le Goazigo A, Audinot V, Chomarat P, Coge F, Nosjean O, Rodriguez M et al. 2007 Comment on 'obestatin, a peptide encoded by the ghrelin gene, opposes ghrelin's effects on food intake'. Science 315 766c.

Chu KM, Chow KBS, Leung PK, Lau PN, Chan CB, Cheng CHK \& Wise H 2007 Over-expression of the truncated ghrelin receptor polypeptide attenuates the constitutive activation of phosphatidylinositol-specific phospholipase $\mathrm{C}$ by ghrelin receptors but has no effect on ghrelinstimulated extracellular signal-regulated kinase $1 / 2$ activity. International Journal of Biochemistry and Cell Biology 39 752-764.

Egerod KL, Holst B, Petersen PS, Hansen JB, Mulder J, Hökfelt T \& Schwartz TW 2007 GPR 39 splice variants versus antisense gene LYPD1 - expression and regulation in gastrointestinal tract, endocrine pancreas, liver and white adipose tissue. Molecular Endocrinology 21 1685-1698.

Feighner SD, Tan CP, McKee KK, Palyha OC, Hreniuk DL, Pong SS, Austin CP, Figueroa D, MacNeil D, Cascieri MA et al. 1999 Receptor for motilin identified in the human gastrointestinal system. Science 284 2184-2188.

Gourcerol G, St-Pierre DH \& Tache Y 2007 Lack of obestatin effects on food intake: should obestatin be renamed ghrelin-associated peptide (GAP)? Regulatory Peptides 141 1-7.

Holst B \& Schwartz TW 2004 Constitutive ghrelin receptor activity as a signaling set-point in appetite regulation. Trends in Pharmacological Sciences $\mathbf{2 5}$ 113-117.

Holst B, Cygankiewicz A, Jensen TH, Ankersen M \& Schwartz TW 2003 High constitutive signaling of the ghrelin receptor-identification of a potent inverse agonist. Molecular Endocrinology 17 2201-2210.

Holst B, Holliday ND, Bach A, Elling CE, Cox HM \& Schwartz TW 2004 Common structural basis for constitutive activity of the ghrelin receptor family. Journal of Biological Chemistry 279 53806-53817.

Holst B, Egerod KL, Schild E, Vickers SP, Cheetham S, Gerlach LO, Storjohann L, Stidsen CE, Jones R, Beck-Sickinger AG et al. 2007 GPR39 signaling is stimulated by zinc ions but not by obestatin. Endocrinology 148 13-20.

Howard AD, Feighner SD, Cully DF, Arena JP, Liberator PA, Rosenblum CI, Hamelin M, Hreniuk DL, Palyha OC, Anderson J et al. 1996 A receptor in pituitary and hypothalamus that functions in growth hormone release. Science 273 974-977.

Jackson VR, Nothacker HP \& Civelli O 2006 GPR39 receptor expression in the mouse brain. Neuroreport 17 813-816. 
Karpa KD, Lin R, Kabbani N \& Levenson R 2000 The dopamine D3 receptor interacts with itself and the truncated D3 splice variant D3nf: D3-D3nf interaction causes mislocalization of D3 receptors. Molecular Pharmacology 58 677-683.

Kim MS, Yoon CY, Park KH, Shin CS, Park KS, Kim SY, Cho BY \& Lee HK 2003 Changes in ghrelin and ghrelin receptor expression according to feeding status. Neuroreport 14 1317-1320.

Kojima M \& Kangawa K 2005 Ghrelin: structure and function. Physiological Reviews 85 495-522.

Kojima M, Hosoda H, Date Y, Nakazato M, Matsuo H \& Kangawa K 1999 Ghrelin is a growth-hormone-releasing acylated peptide from stomach. Nature 402 656-660.

Kumar S, Tamura K \& Nei M 2004 MEGA3: integrated software for molecular evolutionary genetics analysis and sequence alignment. Briefings in Bioinformatics 5 150-163.

Lauwers E, Landuyt B, Arckens L, Schoofs L \& Luyten W 2006 Obestatin does not activate orphan $\mathrm{G}$ protein-coupled receptor GPR39. Biochemical and Biophysical Research Communications 351 21-25.

Leung PK, Chow KBS, Lau PN, Chu KM, Chan CB, Cheng CHK \& Wise H 2007 The truncated ghrelin receptor polypeptide (GHS-R1b) acts as a dominant-negative mutant of the ghrelin receptor. Cellular Signalling 19 1011-1022.

Li Y, Liu X, Zhang Y, Zhu P \& Lin H 2007 Molecular cloning, characterization and distribution of two types of growth hormone receptor in orange-spotted grouper (Epinephelus coioides). General and Comparative Endocrinology 152 111-122.

Ling K, Wang P, Zhao J, Wu YL, Cheng ZJ, Wu GX, Hu W, Ma L \& Pei G 1999 Five-transmembrane domains appear sufficient for a $G$ proteincoupled receptor: functional five-transmembrane domain chemokine receptors. PNAS $967922-7927$.

Livak KJ \& Schmittgen TD 2001 Analysis of relative gene expression data using real-time quantitative PCR and the $2^{-\Delta \Delta C_{\mathrm{t}}}$ method. Methods $25402-408$.

McElvaine AT \& Mayo KE 2006 A dominant-negative human growth hormone-releasing hormone (GHRH) receptor splice variant inhibits GHRH binding. Endocrinology 147 1884-1894.

McKee KK, Tan CP, Palyha OC, Liu J, Feighner SD, Hreniuk DL, Smith RG, Howard AD \& Van der Ploeg LH 1997 Cloning and characterization of two human $\mathrm{G}$ protein-coupled receptor genes (GPR38 and GPR39) related to the growth hormone secretagogue and neurotensin receptors. Genomics $\mathbf{4 6}$ 426-434.

Moechars D, Depoortere I, Moreaux B, de Smet B, Goris I, Hoskens L, Daneels G, Kass S, Ver Donck L, Peeters T et al. 2006 Altered gastrointestinal and metabolic function in the GPR39-obestatin receptorknockout mouse. Gastroenterology 131 1131-1141.

Nakamura K, Yamashita S, Omori Y \& Minegishi T 2004 A splice variant of the human luteinizing hormone (LH) receptor modulates the expression of wild-type human LH receptor. Molecular Endocrinology 18 1461-1470.
Nogueiras R, Pfluger P, Tovar S, Arnold M, Mitchell S, Morris A, Perez-Tilve D, Vazquez MJ, Wiedmer P, Castaneda TR et al. 2007 Effects of obestatin on energy balance and growth hormone secretion in rodents. Endocrinology 148 21-26.

Pantel J, Legendre M, Cabrol S, Hilal L, Hajaji Y, Morisset S, Nivot S, VieLuton M-P, Grouselle D, de Kerdanet M et al. 2006 Loss of constitutive activity of the growth hormone secretagogue receptor in familial short stature. Journal of Clinical Investigation 116 760-768.

Schwartz TW, Frimurer TM, Holst B, Rosenkilde MM \& Elling CE 2006 Molecular mechanism of 7TM receptor activation-a global toggle switch model. Annual Review of Pharmacology and Toxicology 46 481-519.

Vong QP, Chan KM \& Cheng CHK 2003 Quantification of common carp (Cyprinus carpio) IGF-I and IGF-II mRNA by real-time PCR: differential regulation of expression by GH. Journal of Endocrinology 178 513-521.

Wang HJ, Geller F, Dempfle A, Schauble N, Friedel S, Lichtner P, FontenlaHorro F, Wudy S, Hagemann S, Gortner L et al. 2004 Ghrelin receptor gene: identification of several sequence variants in extremely obese children and adolescents, healthy normal-weight and underweight students, and children with short normal stature. Journal of Clinical Endocrinology and Metabolism 89 157-162.

Woolf PJ \& Linderman JJ 2003 Self organization of membrane proteins via dimerization. Biophysical Chemistry 104 217-227.

Yada T, Muto K, Azuma T, Hyodo S \& Schreck CB 2005 Cortisol stimulates growth hormone gene expression in rainbow trout leucocytes in vitro. General and Comparative Endocrinology 142 248-255.

Yamamoto I, Numao M, Sakaguchi Y, Tsushima N \& Tanaka M 2007 Molecular characterization of sequence and expression of chicken GPR39. General and Comparative Endocrinology 151 128-134.

Yeung CM, Chan CB, Woo NYS \& Cheng CHK 2006 Seabream ghrelin: cDNA cloning, genomic organization and promoter studies. Journal of Endocrinology 189 365-379.

Zhang JV, Ren PG, Avsian-Kretchmer O, Luo CW, Rauch R, Klein C, Klein C \& Hsueh AJ 2005 Obestatin, a peptide encoded by the ghrelin gene, opposes ghrelin's effects on food intake. Science 310 996-999.

Zhang JV, Klein C, Ren PG, Kass S, Donck LV, Moechars D \& Hsueh AJW 2007 Response to comment on 'obestatin, a peptide encoded by the ghrelin gene, opposes ghrelin's effects on food intake'. Science 315 766d.

Received in final form 9 September 2008

Accepted 10 September 2008

Made available online as an Accepted Preprint 23 September 2008 